OPEN ACCESS

Edited by:

Krystyna Pierzchala-Koziec

University of Agriculture in

Krakow, Poland

Reviewed by:

Tom V. Smulders,

Newcastle University, United Kingdom

Takeshi Ohkubo,

Ibaraki University, Japan

*Correspondence:

Seong W. Kang

swkang@uark.edu

Specialty section:

This article was submitted to

Avian Physiology,

a section of the journal

Frontiers in Physiology

Received: 10 June 2021 Accepted: 20 September 2021

Published: 21 October 2021

Citation:

Kang SW (2021) Central Nervous

System Associated With Light

Perception and Physiological

Responses of Birds.

Front. Physiol. 12:723454.

doi: 10.3389/fphys.2021.723454

\section{Central Nervous System Associated With Light Perception and Physiological Responses of Birds}

\author{
Seong W. Kang* \\ Department of Poultry Science, Center of Excellence for Poultry Science, University of Arkansas, Fayetteville, AR, \\ United States
}

Environmental light that animal receives (i.e., photoperiod and light intensity) has recently been shown that it affects avian central nervous system for the physiological responses to the environment by up or downregulation of dopamine and serotonin activities, and this, in turn, affects the reproductive function and stress-related behavior of birds. In this study, the author speculated on the intriguing possibility that one of the proposed avian deep-brain photoreceptors (DBPs), i.e., melanopsin (Opn4), may play roles in the dual sensory-neurosecretory cells in the hypothalamus, midbrain, and brain stem for the behavior and physiological responses of birds by light. Specifically, the author has shown that the direct light perception of premammillary nucleus dopamine-melatonin (PMM DA-Mel) neurons is associated with the reproductive activation in birds. Although further research is required to establish the functional role of Opn4 in the ventral tegmental area (VTA), dorsal raphe nucleus, and caudal raphe nucleus in the light perception and physiological responses of birds, it is an exciting prospect because the previous results in birds support this hypothesis that Opn4 in the midbrain DA and serotonin neurons may play significant roles on the light-induced welfare of birds.

Keywords: light, melanopsin (Opn4), premammillary nucleus, ventral tegmental area, raphe nucleus, dopamine, serotonin, welfare

\section{INTRODUCTION}

Light perception and integration of photic information in the diurnal animals are critical for their proper adaptation to the environment, and therefore, animals can respond to daily and annual environmental change (Chmura et al., 2019; Hussein et al., 2021). Light plays a central role in modulating animal behavior and is a critical environmental factor that can affect the physiological processes, performance, and welfare of many animals and birds (Wilson and Cunningham, 1980; Manser, 1996; Deep et al., 2010; Fernandes et al., 2013; Aulsebrook et al., 2021). The physiological roles and effects of light include facilitating sight, regulating reproductive hormone release, and affecting social behavior. The most visible physiological effects of light on birds are the effect of photoperiod and light intensity on the seasonal reproduction, health, and behavior of birds (Deep et al., 2010; Olanrewaju et al., 2018; ViviD and Bentley, 2018). 
Several studies provide evidence that light can affect the central physiology of animals independent of retinal function (Chiu et al., 1975; Routtenberg et al., 1978; Underwood et al., 1984; Wade et al., 1988; Fernandes et al., 2013). In avian species, photoperiodic synchronization is achieved independently of the pineal melatonin through direct light perception by avian deepbrain photoreceptors (DBPs), which project directly to the median eminence near the pars tuberalis (PT) in the anterior pituitary (Kang et al., 2010; Nakane et al., 2010; Chmura et al., 2019). However, evidence is not available regarding the pathway used by the photoperiodic message to reach the PT independently of pineal melatonin in mammals. The melatonin-independent photoperiodic entrainment of the annual thyroid-stimulating hormone (TSH) rhythm was reported in the European hamster, suggesting the presence of the non-visual DBPs in mammals (Saenz De Miera et al., 2018). Interestingly, encephalopsin (Opn3) was found to be expressed in different areas of the rodent brain, indicating a potential role of Opn3 in the non-visual photic process due to the changes in light (Blackshaw and Snyder, 1999; Nissila et al., 2012).

The initiation of light-induced physiological change is particularly important for diurnal animals such as mammals and birds. However, those within the avian brain have not been studied extensively. In this study, the author explored and derived how non-visual photoreceptive cells in the avian brain may connect to circuits controlling the aspects of feeding and emotional behaviors, which will provide an intriguing perspective on how environmental light can be a critical cue for the welfare of birds.

\section{EFFECT OF LIGHT ON THE BEHAVIOR AND PHYSIOLOGY OF BIRDS}

Light information characterizing the particular day length (i.e., photoperiod) and intensity can be stored within the organism and subsequently used to provide time signals for the adjustments of the physiological behavior of animals (Farner and Wingfield, 1980; Gwinner, 1989; Brandstatter et al., 2000). Animals must be able to discriminate between short and long days to perform photoperiodic time measurement. The differences of circadian changes related to the reproductive activation between mammals and avian species were well-reviewed by recent reports (Ikegami and Yoshimura, 2013; Kuenzel et al., 2015; ViviD and Bentley, 2018). In comparison with mammals, the avian circadian pacemaking system seems to be more complicated, being composed of at least three major components containing autonomous circadian oscillators as follows: the pineal gland, the retina, and a central nervous hypothalamic component possibly equivalent to the mammalian suprachiasmatic nucleus (SCN). The avian pineal organ contains photoreceptors with different photopigments including melanopsin (Opn4, an opsin-based photopigment), and synthesizes and secretes melatonin which is regulated by light (Sato, 2001; Kang et al., 2007, 2010).

The effects of artificial light on wild birds are critical for their various biological responses. Especially, artificial light at night alters natural light/dark cycles to be problematic for many avian species, suggesting that disrupting circadian rhythms causes multiple direct and indirect physiological consequences of birds because the unnatural sleep deprivation is associated with cardiovascular disease and endocrine disruption and has a profound effect on the circadian expression of genes associated with the immune and stress response (Dominoni et al., 2016).

Light intensity has a significant effect on the behavior, diurnal activity, and immune function of chickens (Blatchford et al., 2009). When birds are in the higher light intensity, they show a more dramatic circadian rhythm, spending more time active, eating and drinking, walking, foraging, and preening during the photophase (light), and resting more time during the scotophase (dark) compared with birds kept at lower light intensities (Alvino et al., 2009; Blatchford et al., 2009; Rault et al., 2017). The rhythms of the multiunit neuronal activity in the premammillary nucleus (PMM) of the caudal hypothalamus of temperate zone bird were demonstrated to show the photoperiod-dependent durations of high activity (Kang et al., 2007; El Halawani et al., 2009). Moreover, in the follow-up confirmation study, low light intensity (10 lux) could not activate PMM in the turkey hypothalamus even in long-day photoperiod (Moore et al., 2018), indicating that light intensity is also a key stimulant of initiation of avian reproductive function as well as photoperiod in avian species. Melanopsin (Opn4) is one of the DBPs which was characterized in the PMM of female turkey (Kang et al., 2007, 2009, 2010; El Halawani et al., 2009; Leclerc et al., 2010).

\section{AVIAN DBP Opn4 FOR LIGHT PERCEPTION}

The primary system to detect avian photoperiodic information has been thought to be non-retinal, non-pineal DBPs (Benoit and Assenmacher, 1953; Menaker et al., 1970; Yokoyama et al., 1978). Three DBPs (i.e., Opn4, Opsin 5, and Vertebrate ancient opsin) were proposed in the avian brain that responds to photoperiodic information affecting the onset and development of the reproductive function, and all three types of DBPs appear to be involved in priming the neuroendocrine system to activate the reproductive functions of birds (Halford et al., 2009; Kang et al., 2010; Nakane et al., 2010; Kang and Kuenzel, 2015). In this study, the author focused only on Opn4.

Melanopsin (Opn4) was first discovered by Provencio et al. (1998) in the photosensitive melanophores of Xenopus skin. In situ hybridization studies demonstrated that Opn4 mRNA is also expressed in other photosensitive tissues, such as the retina, the magnocellular preoptic nucleus, and the SCN in the brain (Brown and Robinson, 2004). Later, several studies make Opn4 an attractive candidate for circadian photopigment and nonvisual photic responses (Gooley et al., 2003; Hannibal et al., 2013). In non-mammalian vertebrates, Opn4 has two isoforms, namely, mammal-like Opn4m and Xenopus-like Opn4x (Bellingham et al., 2006).

Avian Opn4 expression and functional role in the photoperiodic activation of reproductive function were reported in several avian species (Bailey and Cassone, 2005; Kang et al., 2010; Potter et al., 2018; Nakane et al., 2019). A recent study on Japanese quail showed the possible functional role of 

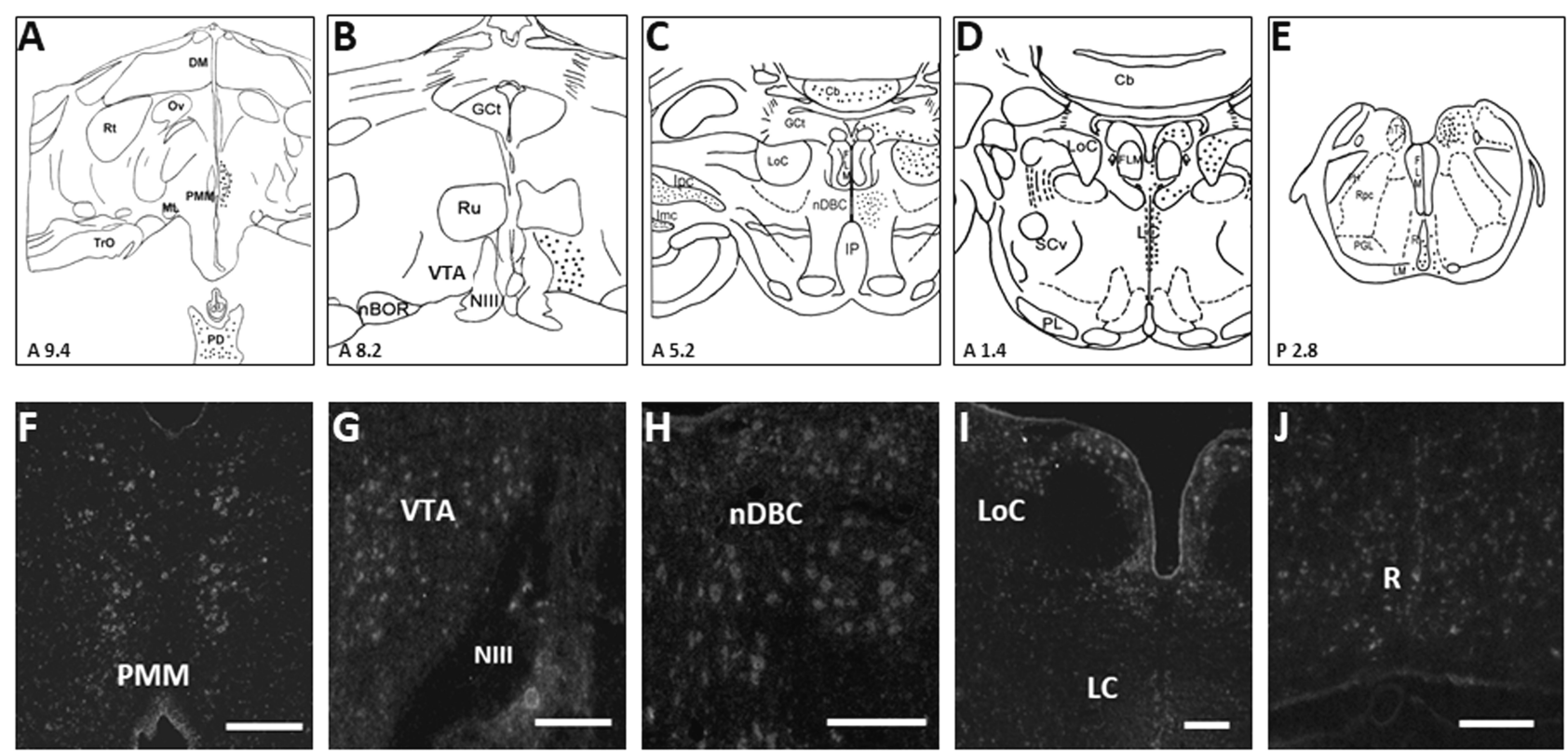

FIGURE 1 | Schematic drawings of rostral-to-caudal (A-E) coronal sections, showing the distribution of turkey Xenopus-like melanopsin (tOpn4x) expression labeled neurons (filled circles) of the turkey hen. Coronal illustrations were drawn from an unpublished turkey brain atlas with nomenclature taken from a chicken atlas (Kuenzel and Masson, 1988) and the revised nomenclature for avian brains (Reiner et al., 2004). Representative photomicrographs (F-J) showing the distribution of tOpn4X mRNA labeled neurons in the PMM, VTA, nDBC, LoC, LC, and R (refer to the abbreviations given below). A specific tOpn4x cRNA probe was used for in situ hybridization histochemistry (ISH). Darkfield photomicrographs of turkey brain sections processed for ISH with ${ }^{33} \mathrm{P}$-labeled tOpn4 antisense cRNA probes. Scale bar: $100 \mu \mathrm{m}$ (G,H,J), $200 \mu \mathrm{m}$ (F,I). The following abbreviations are used in the figure: Cb, cerebellum; DM, dorsomedial hypothalamic nucleus; MLF, medial longitudinal fasciculus; GCt, mesencephalic central gray; Ipc, parvocellular nucleus Isthmi; Imc, magnocellular nucleus isthmi; IP, interpeduncular nucleus; LC, caudal linear nucleus; LM, medial lemniscus; LoC, locus coeruleus; ML, lateral mammillary nucleus; nBOR, nucleus of the basal optic root; nDBC, nucleus decussationis brachiorum conjunctivorum; NIII, third cranial nerve; nTS, nucleus of the solitary tract; Ov, nucleus ovoidalis; PD, pars distalis; PH, plexus of Horsley; PL, lateral pontine nuclei; PMM, premammillary nucleus; R, raphe nucleus; Rpc, parvocellular reticular nucleus; Rt, nucleus rotundus; Ru, nucleus ruber; SCv, nucleus subcoeruleus ventralis; TrO, tractus opticus; VTA, ventral tegmental area (Modified from Kang et al., 2010).

Opn4 in the mediobasal hypothalamus by evaluating an action spectrum for the expression of photoperiodically controlled beta subunit of TSH in the PT of the pituitary gland (Nakane et al., 2019). Interestingly, it has been suggested that Opn4 may have additional physiological roles beyond the reproductive system in the Pekin duck (Van Wyk and Frakey, 2021).

In mammals, specific populations within PMM were genetically defined as dopaminergic (DAergic) neurons and activated in specific social contexts and functions via glutamate release to regulate social interactions; moreover, mammalian PMM has a projection of the catecholaminergic input from locus coeruleus (LoC) (Sobrinho and Canteras, 2011; Soden et al., 2016).

Avian PMM neurons co-express both dopamine and melatonin (DA-MEL, Kang et al., 2007) and are activated by light provided during the photosensitive phase for reproductive stimulation (Thayananuphat et al., 2007b). The regulation of rhythmic DAergic/melatoninergic (MELergic) activity may involve clock genes, which localize and cycle rhythmically within DA/MEL neurons (Leclerc et al., 2010). Moreover, light pulses that are provided during the photosensitive phase for reproductive stimulation activate these neurons, as indicated by the induction of $c$-fos (Thayananuphat et al., 2007a) and the upregulation of Cryl and Per3 genes (Leclerc et al., 2010).
Dopamine and MEL expressing neurons of avian PMM have been shown to have dual functionality, which consists of sensory of light information by Opn4 and neurosecretory functions by the diurnal activities of DA and MEL (Kang et al., 2007, 2009, 2010; Figures 1A,F), suggesting that PMM may be a conserved dual sensory-neurosecretory unit in avian species as suggested in the lower vertebrates (Tessmar-Raible et al., 2007; Conzelmann et al., 2013).

\section{Opn4 EXPRESSION IN THE DOPAMINERGIC AND SEROTONERGIC NUCLEI AND ITS POSSIBLE ROLES IN THE WELFARE OF BIRDS}

Photoreceptor Opn4 was observed in the brain areas that are associated with DA and serotonin [5-hydroxytryptamine (5-HT)] in birds (Kang et al., 2010), which were not appreciated hitherto (Figures 1B-E,G-J). It may be of interest to speculate that direct light perception may be involved in the physiological function of DA and 5-HT neurons in the avian brain. Light-induced feed intake in birds may be directly stimulated by central Opn4 because tryptophan hydroxylase 2 (TPH2: rate-limiting enzyme of serotonin biosynthesis) in 
the dorsal raphe nucleus (DRN) is also associated with food intake and energy balance (Flores et al., 2018; Liu et al., 2021).

Dopamine is predominantly synthesized in the ventral tegmental area (VTA) and substantia nigra (SN) of the midbrain. Dopaminergic neurons in the VTA integrate complex inputs to convert multiple signals that influence motivated behaviors via various neural projections underlying the different functions of these neurons in psychological processes and brain diseases (Beier et al., 2015; Bouarab et al., 2019). In mammals, the important roles of DA neurons were discovered in numerous behavioral or psychological processes other than rewards, such as aversion, depression, fear, social behavior, stress, and movement coordination (Pani et al., 2000; BrombergMartin et al., 2010; Zweifel et al., 2011; Lammel et al., 2012; Chaudhury et al., 2013; Matsumoto and Takada, 2013; Friedman et al., 2014; Walsh et al., 2014; Grace, 2016; Holly and Miczek, 2016). The major brain structures associated with positive emotion are the amygdala complex and nucleus accumbens (Janak and Tye, 2015). Importantly, the nucleus accumbens is the terminal site of the DAergic mesolimbic axis originating in the VTA (Ikemoto, 2007; Holly and Miczek, 2016). Ventral tegmental area neurons have long been implicated in feeding behaviors, and major neurons are DAergic neurons (about 60\% of VTA neurons) (Ungless and Grace, 2012; Meye and Adan, 2014). In addition to DAergic neurons, VTA also contains gamma-aminobutyric acid (GABA) and glutamate neurons that account for about 35 and $2-3 \%$ of VTA neurons, respectively (Nair-Roberts et al., 2008; Taylor et al., 2014; Miranda-Barrientos et al., 2021). Besides DA, GABA, and glutamate neurons, several studies reported serotonergic (5-HTergic) neurons in the VTA of mammalian and avian brains (Kang et al., 2009; Carkaci-Salli et al., 2011; Morales and Margolis, 2017; Smith et al., 2019). Interestingly, the optogenetic activation of VTA GABAergic neurons stimulates food intake and anxiety-like behavior in mice (Chen et al., 2020).

The avian VTA contains cell bodies that label positively for tyrosine hydroxylase $(\mathrm{TH}$; the rate-limiting enzyme in catecholamine biosynthesis) but not DA- $\beta$-hydroxylase (which is involved in converting DA to norepinephrine), indicating that the major population of avian VTA is DAergic neurons (Kang et al., 2009, Figure 2). The electrophysiological and pharmacological properties of VTA neurons have been studied using whole-cell recordings in the brain slices of birds (zebra finch) (Gale and Perkel, 2006), showing that zebra finch VTA DAergic neurons possess physiological properties very similar to those of mammalian DAergic neurons and also contain non-DAergic neurons similar to GABAergic neurons in the mammalian VTA. In addition, avian VTA DAergic neurons densely innervate the striatal areas of the basal ganglia and project more moderately to several other regions of the telencephalon, and the pharmacological agents and lesions targeting the DAergic system have many similar behavioral effects in birds and mammals (Durstewitz et al., 1999). Therefore, these results provide strong evidence for anatomical, physiological, and functional similarities

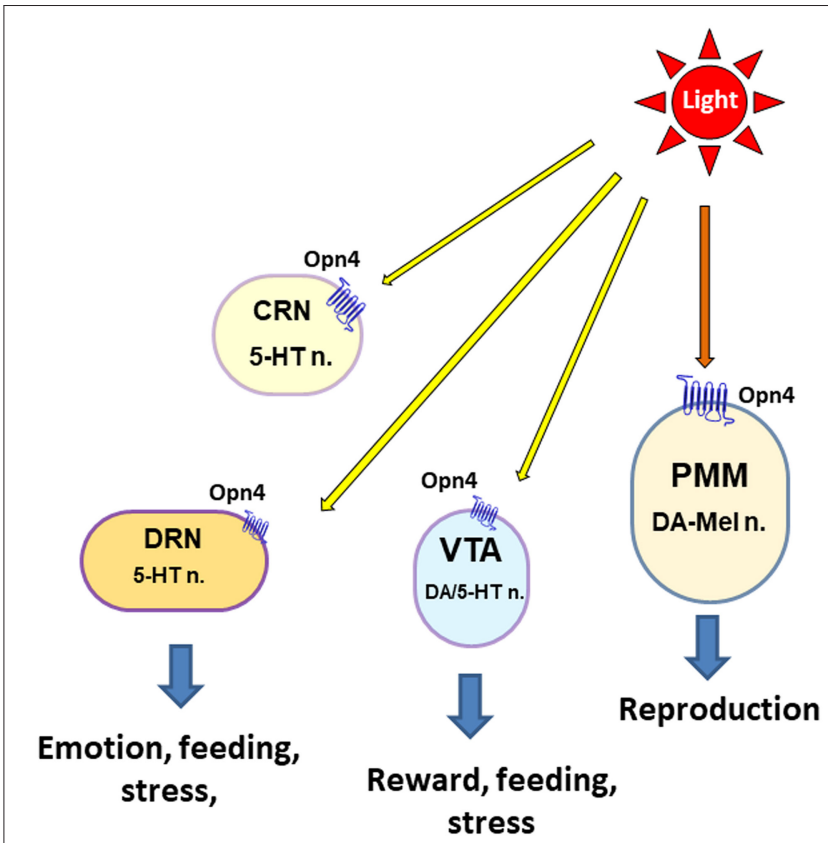

FIGURE 2 | Schematic overview of extraocular light perception in the midbrain and brain stem of avian species for the physiological response. The following abbreviations are used in the figure: $5-\mathrm{HT}$, serotonin; DA, dopamine; CRN, caudal raphe nucleus; DRN, dorsal raphe nucleus; $n$, neuron; PMM, premammillary nucleus; VTA, ventral tegmental area.

between the VTA DAergic systems of mammals and birds (Gale and Perkel, 2006).

The distribution of 5-HT immunoreactivity and TPH2 mRNA expression was reported in the avian brain such as VTA, DRN, and caudal raphe nucleus (CRN) (Cozzi et al., 1991; Challet et al., 1996; Kang et al., 2009). The presence of TPH2positive neurons in the VTA may provide an area of further investigation involving interactions between 5-HTergic and DAergic systems within the VTA (Carkaci-Salli et al., 2011). Serotonin is one of the main neurotransmitters to regulate the parasympathetic nervous system (PNS) and is involved in emotional states caused by stress, pain, or the availability of food (Chamas et al., 1999; Mosienko et al., 2012), while DA acts on the sympathetic nervous system (SNS). Serotonergic neurons can be identified based on the presence of TPH2 mRNA expression, and thereby the TPH2 expression levels can be used as a specific marker for 5-HT generation (Chamas et al., 1999; Kang et al., 2009, 2020; Carkaci-Salli et al., 2011; Liu et al., 2021). The DRN is a heterogeneous brain stem nucleus located in the midbrain and pons, which is involved in the control of various physiological functions, such as learning and memory (Michelsen et al., 2008). The most abundant neurotransmitter in the DRN is serotonin, and the TPH2 mRNA expression was observed in the avian DRN such as nucleus decussationis brachiorum conjunctivorum (nDBC), LoC, and caudal linear nucleus (LC) (Kang et al., 2009, Figure 2). 
The presence of both DA and 5-HT systems in the VTA indicates that avian VTA is the critical area of the midbrain involved in the welfare of avian species (Kang et al., 2009, 2020; Carkaci-Salli et al., 2011). Several studies have proposed that DA and 5-HT could serve as positive indicators of animal welfare (Algers et al., 2007; Boissy et al., 2007; Polter and Kauer, 2014). Stress and negative experience alter the 5-HT metabolism in the brain by stimulating 5 -HT turnover in the areas innervated by 5 -HTergic neurons (Clement et al., 1993; Inoue et al., 1994; Amat et al., 1998). In mammals, repeated immobilization stress increased the TPH2 gene expression levels in the raphe nuclei of the brain stem (Chamas et al., 1999; Walther et al., 2003), indicating the elevation of 5-HT metabolism. In the recent study of DA and 5-HT activity, 5-HTergic and DAergic activities respond differently to light intensity and light intensity preference, and these results suggest the beneficial effects of dual intensity lighting program on the protection of the central nervous system of birds (Kang et al., 2020).

\section{PERSPECTIVE}

Animals explore their surroundings to secure resources such as food, water, and shelter, and the regulation of their reproductive system for producing offspring depends on the environment day-and-night light condition.

The data discussed in this study and the previous light intensity study (Kang et al., 2020) suggest the possible roles of Opn4 in the VTA and DRN/CRN on the direct light perception for the physiological responses of birds such as

\section{REFERENCES}

Algers, B., Lundeheim, N., Boyle, L. A., Broom, D. M., Eliasson-Selling, L., Holmgren, N., et al. (2007). Thoughts on farm animal welfare. J. Am. Vet. Med. Assoc. 230, 185-186; author reply 186-187.

Alvino, G. M., Blatchford, R. A., Archer, G. S., and Mench, J. A. (2009). Light intensity during rearing affects the behavioural synchrony and resting patterns of broiler chickens. Br. Poult. Sci. 50, 275-283. doi: 10.1080/00071660902942775

Amat, J., Matus-Amat, P., Watkins, L. R., and Maier, S. F. (1998). Escapable and inescapable stress differentially alter extracellular levels of 5HT in the basolateral amygdala of the rat. Brain Res. 812, 113-120. doi: 10.1016/s0006-8993(98)00960-3

Aulsebrook, A. E., Johnsson, R. D., and Lesku, J. A. (2021). Light, sleep and performance in diurnal birds. Clocks Sleep 3, 115-131. doi: 10.3390/clockssleep3010008

Bailey, M. J., and Cassone, V. M. (2005). Melanopsin expression in the chick retina and pineal gland. Brain Res. Mol. Brain Res. 134, 345-348. doi: 10.1016/j.molbrainres.2004.11.003

Beier, K. T., Steinberg, E. E., Deloach, K. E., Xie, S., Miyamichi, K., Schwarz, L., et al. (2015). Circuit architecture of VTA dopamine neurons revealed by systematic input-output mapping. Cell 162, 622-634. doi: 10.1016/j.cell.2015. 07.015

Bellingham, J., Chaurasia, S. S., Melyan, Z., Liu, C., Cameron, M. A., Tarttelin, E. E., et al. (2006). Evolution of melanopsin photoreceptors: discovery and characterization of a new melanopsin in nonmammalian vertebrates. PLoS Biol. 4:e254. doi: 10.1371/journal.pbio.0040254 feeding behavior and welfare. Although this observation makes the hypothesis that Opn4 is a positive candidate photoreceptor associated with direct light perception in the ancient brain (i.e., hypothalamus and brain stem) of birds, the functional role of Opn 4 should be tested in the future study.

\section{DATA AVAILABILITY STATEMENT}

The original contributions presented in the study are included in the article, further inquiries can be directed to the corresponding author/s.

\section{AUTHOR CONTRIBUTIONS}

SK contributed to the conception, drafted the manuscript, edited and revised the manuscript, and approved the final version of the manuscript.

\section{FUNDING}

This study was financially supported by the US Poultry and Egg Association Research Grant.

\section{ACKNOWLEDGMENTS}

The author thanks his current and past collaborators Dr. Karen Christensen, Dr. Wayne J. Kuenzel, and Dr. Mohamed El Halawani for their valuable contributions to the research underpinning this study.
Benoit, J., and Assenmacher, I. (1953). [Role of superficial and deep photoreceptors in photostimulation of gonads in birds]. J. Physiol. (Paris) 45, 34-37.

Blackshaw, S., and Snyder, S. H. (1999). Encephalopsin: a novel mammalian extraretinal opsin discretely localized in the brain. J. Neurosci. 19, 3681-3690.

Blatchford, R. A., Klasing, K. C., Shivaprasad, H. L., Wakenell, P. S., Archer, G. S., and Mench, J. A. (2009). The effect of light intensity on the behavior, eye and leg health, and immune function of broiler chickens. Poult. Sci. 88, 20-28. doi: 10.3382/ps.2008-00177

Boissy, A., Manteuffel, G., Jensen, M. B., Moe, R. O., Spruijt, B., Keeling, L. J., et al. (2007). Assessment of positive emotions in animals to improve their welfare. Physiol. Behav. 92, 375-397. doi: 10.1016/j.physbeh.2007.02.003

Bouarab, C., Thompson, B., and Polter, A. M. (2019). VTA GABA neurons at the interface of stress and reward. Front. Neural Circuits 13, 78. doi: 10.3389/fncir.2019.00078

Brandstatter, R., Kumar, V., Abraham, U., and Gwinner, E. (2000). Photoperiodic information acquired and stored in vivo is retained in vitro by a circadian oscillator, the avian pineal gland. Proc. Natl. Acad. Sci. U.S.A. 97, 12324-12328. doi: $10.1073 /$ pnas.200354997

Bromberg-Martin, E. S., Matsumoto, M., and Hikosaka, O. (2010). Dopamine in motivational control: rewarding, aversive, and alerting. Neuron 68, 815-834. doi: 10.1016/j.neuron.2010.11.022

Brown, R. L., and Robinson, P. R. (2004). Melanopsin-shedding light on the elusive circadian photopigment. Chronobiol. Int. 21, 189-204. doi: $10.1081 /$ cbi-120037816

Carkaci-Salli, N., Salli, U., Kuntz-Melcavage, K. L., Pennock, M. M., Ozgen, H., Tekin, I., et al. (2011). TPH2 in the ventral tegmental area of the male rat brain. Brain Res. Bull. 84, 376-380. doi: 10.1016/j.brainresbull.2011.01.006 
Challet, E., Miceli, D., Pierre, J., Reperant, J., Masicotte, G., Herbin, M., et al. (1996). Distribution of serotonin-immunoreactivity in the brain of the pigeon (Columba livia). Anat. Embryol. (Berl.) 193, 209-227. doi: 10.1007/BF00198325

Chamas, F., Serova, L., and Sabban, E. L. (1999). Tryptophan hydroxylase mRNA levels are elevated by repeated immobilization stress in rat raphe nuclei but not in pineal gland. Neurosci. Lett. 267, 157-160. doi: 10.1016/s0304-3940(99)00340-7

Chaudhury, D., Walsh, J. J., Friedman, A. K., Juarez, B., Ku, S. M., Koo, J. W., et al. (2013). Rapid regulation of depression-related behaviours by control of midbrain dopamine neurons. Nature 493, 532-536. doi: 10.1038/nature11713

Chen, L., Lu, Y. P., Chen, H. Y., Huang, S. N., Guo, Y. R., Zhang, J. Y., et al. (2020). Ventral tegmental area GABAergic neurons induce anxiety-like behaviors and promote palatable food intake. Neuropharmacology 173, 108114. doi: 10.1016/j.neuropharm.2020.108114

Chiu, P. S., Lauber, J. K., and Kinnear, A. (1975). Dimensional and physiological lesions in the chick eye as influenced by the light environment. Proc. Soc. Exp. Biol. Med. 148, 1223-1228. doi: 10.3181/00379727-148-38721

Chmura, H. E., Wingfield, J. C., and Hahn, T. P. (2019). Non-photic environmental cues and avian reproduction in an era of global change. J. Avian Biol. 51. doi: $10.1111 /$ jav. 02243

Clement, H. W., Schafer, F., Ruwe, C., Gemsa, D., and Wesemann, W. (1993). Stress-induced changes of extracellular 5-hydroxyindoleacetic acid concentrations followed in the nucleus raphe dorsalis and the frontal cortex of the rat. Brain Res. 614, 117-124. doi: 10.1016/0006-8993(93)91024-m

Conzelmann, M., Williams, E. A., Tunaru, S., Randel, N., Shahidi, R., Asadulina, A., et al. (2013). Conserved MIP receptor-ligand pair regulates Platynereis larval settlement. Proc. Natl. Acad. Sci. U.S.A. 110, 8224-8229. doi: $10.1073 /$ pnas. 1220285110

Cozzi, B., Viglietti-Panzica, C., Aste, N., and Panzica, G. C. (1991). The serotoninergic system in the brain of the Japanese quail. An immunohistochemical study. Cell Tissue Res. 263, 271-284. doi: $10.1007 / \mathrm{BF} 00318769$

Deep, A., Schwean-Lardner, K., Crowe, T. G., Fancher, B. I., and Classen, H. L. (2010). Effect of light intensity on broiler production, processing characteristics, and welfare. Poult. Sci. 89, 2326-2333. doi: 10.3382/ps.2010-00964

Dominoni, D. M., Borniger, J. C., and Nelson, R. J. (2016). Light at night, clocks and health: from humans to wild organisms. Biol. Lett. 12, 20160015. doi: 10.1098/rsbl.2016.0015

Durstewitz, D., Kroner, S., and Gunturkun, O. (1999). The dopaminergic innervation of the avian telencephalon. Prog. Neurobiol. 59, 161-195. doi: 10.1016/s0301-0082(98)00100-2

El Halawani, M. E., Kang, S. W., Leclerc, B., Kosonsiriluk, S., and Chaiseha, Y. (2009). Dopamine-melatonin neurons in the avian hypothalamus and their role as photoperiodic clocks. Gen. Comp. Endocrinol. 163, 123-127. doi: 10.1016/j.ygcen.2008.11.030

Farner, D. S., and Wingfield, J. C. (1980). Reproductive endocrinology of birds. Annu. Rev. Physiol. 42, 457-472. doi: 10.1146/annurev.ph.42.030180.002325

Fernandes, A. M., Fero, K., Driever, W., and Burgess, H. A. (2013). Enlightening the brain: linking deep brain photoreception with behavior and physiology. Bioessays 35, 775-779. doi: 10.1002/bies.201300034

Flores, R. A., Da Silva, E. S., Ribas, A. S., Taschetto, A. P. D., Zampieri, T. T., Donato, J. Jr., et al. (2018). Evaluation of food intake and Fos expression in serotonergic neurons of raphe nuclei after intracerebroventricular injection of adrenaline in free-feeding rats. Brain Res. 1678, 153-163. doi: 10.1016/j.brainres.2017.10.021

Friedman, A. K., Walsh, J. J., Juarez, B., Ku, S. M., Chaudhury, D., Wang, J., et al. (2014). Enhancing depression mechanisms in midbrain dopamine neurons achieves homeostatic resilience. Science 344, 313-319. doi: $10.1126 /$ science. 1249240

Gale, S. D., and Perkel, D. J. (2006). Physiological properties of zebra finch ventral tegmental area and substantia nigra pars compacta neurons. J. Neurophysiol. 96, 2295-2306. doi: 10.1152/jn.01040.2005

Gooley, J. J., Lu, J., Fischer, D., and Saper, C. B. (2003). A broad role for melanopsin in nonvisual photoreception. J. Neurosci. 23, 7093-7106. doi: 10.1523/JNEUROSCI.23-18-07093.2003
Grace, A. A. (2016). Dysregulation of the dopamine system in the pathophysiology of schizophrenia and depression. Nat. Rev. Neurosci. 17, 524-532. doi: $10.1038 / \mathrm{nrn} .2016 .57$

Gwinner, E. (1989). Photoperiod as a modifying and limiting factor in the expression of avian circannual rhythms. J. Biol. Rhythms 4, 237-250. doi: $10.1177 / 074873048900400210$

Halford, S., Pires, S. S., Turton, M., Zheng, L., Gonzalez-Menendez, I., Davies, W. L., et al. (2009). VA opsin-based photoreceptors in the hypothalamus of birds. Curr. Biol. 19, 1396-1402. doi: 10.1016/j.cub.2009.06.066

Hannibal, J., Georg, B., and Fahrenkrug, J. (2013). Differential expression of melanopsin mRNA and protein in Brown Norwegian rats. Exp. Eye Res. 106, 55-63. doi: 10.1016/j.exer.2012.11.006

Holly, E. N., and Miczek, K. A. (2016). Ventral tegmental area dopamine revisited: effects of acute and repeated stress. Psychopharmacology (Berl). 233, 163-186. doi: 10.1007/s00213-015-4151-3

Hussein, A., a,.A., Bloem, E., Fodor, I., Baz, E. S., Tadros, M. M., et al. (2021). Slowly seeing the light: an integrative review on ecological light pollution as a potential threat for mollusks. Environ. Sci. Pollut. Res. Int. 28, 5036-5048. doi: 10.1007/s11356-020-11824-7

Ikegami, K., and Yoshimura, T. (2013). Seasonal time measurement during reproduction. J. Reprod. Dev. 59, 327-333. doi: 10.1262/jrd.2013-035

Ikemoto, S. (2007). Dopamine reward circuitry: two projection systems from the ventral midbrain to the nucleus accumbens-olfactory tubercle complex. Brain Res. Rev. 56, 27-78. doi: 10.1016/j.brainresrev.2007.05.004

Inoue, T., Tsuchiya, K., and Koyama, T. (1994). Regional changes in dopamine and serotonin activation with various intensity of physical and psychological stress in the rat brain. Pharmacol. Biochem. Behav. 49, 911-920. doi: 10.1016/0091-3057(94)90243-7

Janak, P. H., and Tye, K. M. (2015). From circuits to behaviour in the amygdala. Nature 517, 284-292. doi: 10.1038/nature14188

Kang, S. W., Christensen, K. D., Aldridge, D., and Kuenzel, W. J. (2020). Effects of light intensity and dual light intensity choice on plasma corticosterone, central serotonergic and dopaminergic activities in birds, Gallus gallus. Gen. Comp. Endocrinol. 285, 113289. doi: 10.1016/j.ygcen.2019.113289

Kang, S. W., and Kuenzel, W. J. (2015). Deep-brain photoreceptors (DBPs) involved in the photoperiodic gonadal response in an avian species, Gallus gallus. Gen. Comp. Endocrinol. 211, 106-113. doi: 10.1016/j.ygcen.2014.11.020

Kang, S. W., Leclerc, B., Kosonsiriluk, S., Mauro, L. J., Iwasawa, A., and El Halawani, M. E. (2010). Melanopsin expression in dopamine-melatonin neurons of the premammillary nucleus of the hypothalamus and seasonal reproduction in birds. Neuroscience 170, 200-213.

Kang, S. W., Leclerc, B., Mauro, L. J., and El Halawani, M. E. (2009). Serotonergic and catecholaminergic interactions with co-localised dopamine-melatonin neurones in the hypothalamus of the female turkey. J. Neuroendocrinol. 21, 10-19. doi: 10.1111/j.1365-2826.2008.01804.x

Kang, S. W., Thayananuphat, A., Bakken, T., and El Halawani, M. E. (2007). Dopamine-melatonin neurons in the avian hypothalamus controlling seasonal reproduction. Neuroscience 150, 223-233. doi: 10.1016/j.neuroscience.2007.08.031

Kuenzel, W. J., Kang, S. W., and Zhou, Z. J. (2015). Exploring avian deep-brain photoreceptors and their role in activating the neuroendocrine regulation of gonadal development. Poult. Sci. 94, 786-798. doi: 10.3382/ps.2014-4370

Kuenzel, W. J., and Masson, M. (1988). A Stereotaxic Atlas of the Brain of Chick (Gallus domesticus). Baltimore, MD: Johns Hopkins University Press.

Lammel, S., Lim, B. K., Ran, C., Huang, K. W., Betley, M. J., Tye, K. M., et al. (2012). Input-specific control of reward and aversion in the ventral tegmental area. Nature 491, 212-217. doi: 10.1038/nature11527

Leclerc, B., Kang, S. W., Mauro, L. J., Kosonsiriluk, S., Chaiseha, Y., and El Halawani, M. E. (2010). Photoperiodic modulation of clock gene expression in the avian premammillary nucleus. J. Neuroendocrinol. 22, 119-128. doi: 10.1111/j.1365-2826.2009.01942.x

Liu, H., Wang, C., Yu, M., Yang, Y., He, Y., Liu, H., et al. (2021). TPH2 in the dorsal raphe nuclei regulates energy balance in a sex-dependent manner. Endocrinology 162, bqaa183. doi: 10.1210/endocr/bqaa183

Manser, C. E. (1996). Effects of lighting on the welfare of domestic poultry: a review. Anim. Welf. 5, 341-360. doi: 10.1258/002367796780744974 
Matsumoto, M., and Takada, M. (2013). Distinct representations of cognitive and motivational signals in midbrain dopamine neurons. Neuron 79, 1011-1024. doi: 10.1016/j.neuron.2013.07.002

Menaker, M., Roberts, R., Elliott, J., and Underwood, H. (1970). Extraretinal light perception in the sparrow. 3. The eyes do not participate in photoperiodic photoreception. Proc. Natl. Acad. Sci. U.S.A. 67, 320-325. doi: 10.1073/pnas.67.1.320

Meye, F. J., and Adan, R. A. (2014). Feelings about food: the ventral tegmental area in food reward and emotional eating. Trends Pharmacol. Sci. 35, 31-40. doi: 10.1016/j.tips.2013.11.003

Michelsen, K. A., Prickaerts, J., and Steinbusch, H. W. (2008). The dorsal raphe nucleus and serotonin: implications for neuroplasticity linked to major depression and Alzheimer's disease. Prog. Brain Res. 172, 233-264. doi: 10.1016/S0079-6123(08)00912-6

Miranda-Barrientos, J., Chambers, I., Mongia, S., Liu, B., Wang, H. L., MateoSemidey, G. E., et al. (2021). Ventral tegmental area GABA, glutamate, and glutamate-GABA neurons are heterogeneous in their electrophysiological and pharmacological properties. Eur. J. Neurosci. 54, 4061-4084. doi: 10.1111/ejn. 15156

Moore, A. F., Cassone, V. M., Alloway, K. D., and Bartell, P. A. (2018). The premammillary nucleus of the hypothalamus is not necessary for photoperiodic timekeeping in female turkeys (Meleagris gallopavo). PLoS ONE 13, e0190274. doi: 10.1371/journal.pone.0190274

Morales, M., and Margolis, E. B. (2017). Ventral tegmental area: cellular heterogeneity, connectivity and behaviour. Nat. Rev. Neurosci. 18, 73-85. doi: $10.1038 /$ nrn.2016.165

Mosienko, V., Bert, B., Beis, D., Matthes, S., Fink, H., Bader, M., et al. (2012). Exaggerated aggression and decreased anxiety in mice deficient in brain serotonin. Transl. Psychiatry 2, e122. doi: 10.1038/tp. 2012.44

Nair-Roberts, R. G., Chatelain-Badie, S. D., Benson, E., White-Cooper, H., Bolam, J. P., and Ungless, M. A. (2008). Stereological estimates of dopaminergic, GABAergic and glutamatergic neurons in the ventral tegmental area, substantia nigra and retrorubral field in the rat. Neuroscience 152, 1024-1031. doi: 10.1016/j.neuroscience.2008.01.046

Nakane, Y., Ikegami, K., Ono, H., Yamamoto, N., Yoshida, S., Hirunagi, K., et al. (2010). A mammalian neural tissue opsin (Opsin 5) is a deep brain photoreceptor in birds. Proc. Natl. Acad. Sci. U.S.A. 107, 15264-15268. doi: $10.1073 /$ pnas. 1006393107

Nakane, Y., Shinomiya, A., Ota, W., Ikegami, K., Shimmura, T., Higashi, S.-I., et al. (2019). Action spectrum for photoperiodic control of thyroid-stimulating hormone in Japanese quail (Coturnix japonica). PLoS ONE 14:e0222106. doi: 10.1371/journal.pone.0222106

Nissila, J., Manttari, S., Sarkioja, T., Tuominen, H., Takala, T., Timonen, M., et al. (2012). Encephalopsin (OPN3) protein abundance in the adult mouse brain. J. Comp. Physiol. A Neuroethol. Sens. Neural Behav. Physiol. 198, 833-839. doi: 10.1007/s00359-012-0754-x

Olanrewaju, H. A., Miller, W. W., Maslin, W. R., Collier, S. D., Purswell, J. L., and Branton, S. L. (2018). Influence of light sources and photoperiod on growth performance, carcass characteristics, and health indices of broilers grown to heavy weights. Poult. Sci. 97, 1109-1116. doi: 10.3382/ps/ pex426

Pani, L., Porcella, A., and Gessa, G. L. (2000). The role of stress in the pathophysiology of the dopaminergic system. Mol. Psychiatry 5, 14-21. doi: 10.1038/sj.mp. 4000589

Polter, A. M., and Kauer, J. A. (2014). Stress and VTA synapses: implications for addiction and depression. Eur. J. Neurosci. 39, 1179-1188. doi: $10.1111 /$ ejn. 12490

Potter, H., Alenciks, E., Frazier, K., Porter, A., and Fraley, G. S. (2018). Immunolesion of melanopsin neurons causes gonadal regression in Pekin drakes (Anas platyrhynchos domesticus). Gen. Comp. Endocrinol. 256, 16-22. doi: 10.1016/j.ygcen.2017.08.006

Provencio, I., Jiang, G., De Grip, W. J., Hayes, W. P., and Rollag, M. D. (1998). Melanopsin: an opsin in melanophores, brain, and eye. Proc. Natl. Acad. Sci. U.S.A. $95,340-345$

Rault, J. L., Clark, K., Groves, P. J., and Cronin, G. M. (2017). Light intensity of 5 or 20 lux on broiler behavior, welfare and productivity. Poult. Sci. 96, 779-787. doi: $10.3382 /$ ps/pew 423
Reiner, A., Perkel, D. J., Bruce, L. L., Butler, A. B., Csillag, A., Kuenzel, W., et al. (2004). Revised nomenclature for avian telencephalon and some related brainstem nuclei. J. Comp. Neurol. 473, 377-414. doi: 10.1002/cne.20118

Routtenberg, A., Strop, M., and Jerdan, J. (1978). Response of the infant rat to light prior to eyelid opening: mediation by the superior colliculus. Dev. Psychobiol. 11, 469-478. doi: 10.1002/dev.420110510

Saenz De Miera, C., Sage-Ciocca, D., Simonneaux, V., Pevet, P., and Monecke, S. (2018). Melatonin-independent photoperiodic entrainment of the circannual TSH rhythm in the pars tuberalis of the European Hamster. J. Biol. Rhythms 33, 302-317. doi: 10.1177/0748730418 766601

Sato, T. (2001). Sensory and endocrine characteristics of the avian pineal organ. Microsc. Res. Tech. 53, 2-11. doi: 10.1002/jemt.1063

Smith, R. J., Vento, P. J., Chao, Y. S., Good, C. H., and Jhou, T. C. (2019). Gene expression and neurochemical characterization of the rostromedical tegmental nucleus (RMTg) in rats and mice. Brain Struct. Funct. 224, 219-238. doi: 10.1007/s00429-018-1761-7

Sobrinho, C. R., and Canteras, N. S. (2011). A study of the catecholaminergic inputs to the dorsal premammillary nucleus. Neurosci. Lett. 501, 157-162. doi: 10.1016/j.neulet.2011.07.006

Soden, M. E., Miller, S. M., Burgeno, L. M., Phillips, P. E. M., Hnasko, T. S., and Zweifel, L. S. (2016). Genetic isolation of hypothalamic neurons that regulate context-specific male social behavior. Cell Rep. 16, 304-313. doi: 10.1016/j.celrep.2016.05.067

Taylor, S. R., Badurek, S., Dileone, R. J., Nashmi, R., Minichiello, L., and Picciotto, M. R. (2014). GABAergic and glutamatergic efferents of the mouse ventral tegmental area. J. Comp. Neurol. 522, 3308-3334. doi: 10.1002/cne. 23603

Tessmar-Raible, K., Raible, F., Christodoulou, F., Guy, K., Rembold, M., Hausen, H., et al. (2007). Conserved sensory-neurosecretory cell types in annelid and fish forebrain: insights into hypothalamus evolution. Cell 129, 1389-1400. doi: 10.1016/j.cell.2007.04.041

Thayananuphat, A., Kang, S. W., Bakken, T., Millam, J. R., and El Halawani, M. E. (2007a). Rhythm-dependent light induction of the cfos gene in the turkey hypothalamus. J. Neuroendocrinol. 19, 407-417. doi: 10.1111/j.1365-2826.2007.01544.x

Thayananuphat, A., Kang, S. W., Bakken, T., Millam, J. R., and El Halawani, M. E. (2007b). Rhythmic dependent light induction of gonadotrophin-releasing hormone-I expression and activation of dopaminergic neurones within the premammillary nucleus of the turkey hypothalamus. J. Neuroendocrinol. 19, 399-406. doi: 10.1111/j.1365-2826.2007.01545.x

Underwood, H., Binkley, S., Siopes, T., and Mosher, K. (1984). Melatonin rhythms in the eyes, pineal bodies, and blood of Japanese quail (Coturnix coturnix japonica). Gen. Comp. Endocrinol. 56, 70-81. doi: 10.1016/0016-6480(84)90063-7

Ungless, M. A., and Grace, A. A. (2012). Are you or aren't you? Challenges associated with physiologically identifying dopamine neurons. Trends Neurosci 35, 422-430. doi: 10.1016/j.tins.2012.02.003

Van Wyk, B., and Frakey, G. (2021). Ontogeny of OPN4, OPN5, GnRH and GnIH mRNA expression in the posthatch male and female Pekin duck (Anas platyrhynchos domesticus) suggests OPN4 may have additional functions beyond reproduction. Animals 11, 1121. doi: 10.3390/ani11041121

ViviD, D., and Bentley, G.E. (2018). Seasonal reproduction in vertebrates: melatonin synthesis, binding, and functionality using Tinbergen's four questions. Molecules 23, 652. doi: 10.3390/molecules 23030652

Wade, P. D., Taylor, J., and Siekevitz, P. (1988). Mammalian cerebral cortical tissue responds to low-intensity visible light. Proc. Natl. Acad. Sci. U.S.A. 85, 9322-9326. doi: 10.1073/pnas.85.23.9322

Walsh, J. J., Friedman, A. K., Sun, H., Heller, E. A., Ku, S. M., Juarez, B., et al. (2014). Stress and CRF gate neural activation of BDNF in the mesolimbic reward pathway. Nat. Neurosci. 17, 27-29. doi: 10.1038/nn.3591

Walther, D. J., Peter, J. U., Bashammakh, S., Hortnagl, H., Voits, M., Fink, H., et al. (2003). Synthesis of serotonin by a second tryptophan hydroxylase isoform. Science. 299, 76. doi: 10.1126/science.1078197

Wilson, S. C., and Cunningham, F. J. (1980). Effect of increasing day length and intermittent lighting schedules in the domestic hen on plasma concentrations of luteinizing hormone $(\mathrm{LH})$ and the $\mathrm{LH}$ response to exogenous progesterone. Gen. Comp. Endocrinol. 41, 546-553. 
Yokoyama, K., Oksche, A., Darden, T. R., and Farner, D. S. (1978). The sites of encephalic photoreception in phosoperiodic induction of the growth of the testes in the white-crowned sparrow, Zonotrichia leucophrys gambelii. Cell Tissue Res. 189, 441-467. doi: 10.1007/BF00209132

Zweifel, L. S., Fadok, J. P., Argilli, E., Garelick, M. G., Jones, G. L., Dickerson, T. M., et al. (2011). Activation of dopamine neurons is critical for aversive conditioning and prevention of generalized anxiety. Nat. Neurosci. 14, 620-626. doi: $10.1038 / \mathrm{nn} .2808$

Conflict of Interest: The author declares that the research was conducted in the absence of any commercial or financial relationships that could be construed as a potential conflict of interest.
Publisher's Note: All claims expressed in this article are solely those of the authors and do not necessarily represent those of their affiliated organizations, or those of the publisher, the editors and the reviewers. Any product that may be evaluated in this article, or claim that may be made by its manufacturer, is not guaranteed or endorsed by the publisher.

Copyright (c) 2021 Kang. This is an open-access article distributed under the terms of the Creative Commons Attribution License (CC BY). The use, distribution or reproduction in other forums is permitted, provided the original author(s) and the copyright owner(s) are credited and that the original publication in this journal is cited, in accordance with accepted academic practice. No use, distribution or reproduction is permitted which does not comply with these terms. 